\title{
Strategi Peningkatan Kinerja Penyuluh Pertanian dalam Pengembangan Agribisnis di Kabupaten Banyuwangi
}

\section{Strategy to Increase Performance of Agricultural Instructor of Agribusiness Development in Banyuwangi}

\author{
Danang Sudarso Widya Prakoso Joyo Widakdo ${ }^{1}$ \\ ${ }^{1}$ Politeknik Negeri Banyuwangi, Jawa Timur
}

\begin{abstract}
Agribusiness development in Banyuwangi growing supported by the agricultural extension. The role of agricultural extension is needed by communities and farmers. Therefore, strategies are needed to improve its performance, especially with the implementation of the difference between the central government and local governments (regional autonomy). Research related to strategies for improving the performance of agricultural extension workers, especially in Banyuwangi has been done by first analyzing the factors that affect the performance of the extension, which is then analyzed more in depth with the IE method, SWOT and QSPM and eventually obtained agricultural extension strategies for improving performance. The results showed that the strength factor is the suitability of a high enough salary, weakness factor is the lack of monitoring of the performance of agricultural extension, chances are the interest factor be enough agricultural extension, the threat factor is the lack of agricultural extension PNS. Strategic priorities for performance improvement of agricultural extension is the need to evaluate the performance of agricultural extension monitoring periodically, the second priority is additional quota admission counselor civil servants, the third priority the strengthening of IT, the fourth priority intensification of agricultural extension training programs to improve the performance of the performance competencies of agricultural extension, the fifth priority the improvement of cooperation among government agencies to integrate all of the work program for the right target, and the sixth priority poktan role to participate in the establishment of monitoring the performance of agricultural extension. While the managerial implications in the development of agribusiness, there are three themes, namely human resource development extension agent, performance evaluation, and monitoring the performance of agricultural extension.
\end{abstract}

Keywords: The performance of the agricultural instructor, Banyuwangi agribusiness development, strategic priorities, managerial, implication

\begin{abstract}
Abstrak
Tuntutan masyarakat dan petani semakin tinggi terhadap keberadaan penyuluh pertanian. Oleh karena itu, diperlukan strategi untuk meningkatkan kinerjanya, terlebih pada era sekarang yang terdapat perbedaan penyelenggaraan antara pemerintah pusat dengan pemerintah daerah (otonomi daerah). Penelitian terkait dengan strategi peningkatan kinerja penyuluh pertanian khususnya dikabupaten Banyuwangi telah dilakukan dengan terlebih dahulu menganalisis faktor-faktor yang mempengaruhi kinerja penyuluh tersebut, yang selanjutnya dianalisis lebih mendalam dengan metoda IE, SWOT dan QSPM sehingga pada akhirnya didapatkan strategi peningkatan kinerja penyuluh pertanian. Hasil yang didapatkan bahwa yang menjadi faktor kekuatan adalah kesesuaian gaji yang cukup tinggi, faktor kelemahan adalah kurangnya monitoring terhadap kinerja penyuluh pertanian, faktor peluang adalah minat menjadi penyuluh pertanian cukup banyak, faktor ancaman adalah kurangnya penyuluh pertanian PNS. Strategi prioritas untuk peningkatan kinerja penyuluh pertanian adalah perlunya evaluasi monitoring kinerja penyuluh pertanian secara berkala, prioritas kedua yaitu penambahan kuota penerimaan penyuluh PNS, prioritas ketiga penguatan TI, prioritas keempat intensifikasi program pelatihan kinerja penyuluh pertanian untuk meningkatkan kompetensi kinerja penyuluh pertanian, prioritas kelima peningkatan kerjasama antar instansi pemerintah untuk mengintegrasikan semua program kerja agar tepat sasaran, dan prioritas keenam peran poktan untuk ikut melaksanakan monitoring terhadap kinerja penyuluh pertanian. Sedangkan implikasi manajerial dalam pengembangan agribisnis ada tiga tema yaitu SDM penyuluh pertanian, evaluasi kinerja, dan monitoring kinerja penyuluh pertanian.
\end{abstract}

Kata kunci: Kinerja penyuluh pertanian, Pengembangan agribisnis di Banyuwangi, prioritas strategi, implikasi manajerial

\section{Pendahuluan}

Sektor pertanian merupakan sektor ekonomi paling dominan bila diperhatikan berdasarkan struktur ekonomi Kabupaten Banyuwangi. Data Dinas
Pertanian, Kehutanan dan Perkebunan Kabupaten Banyuwangi menunjukkan, sektor pertanian, khususnya tanaman padi produksi pada tahun 2011 sebesar 761.317 ton dan meningkat menjadi 792.753 ton pada tahun 2012 dengan lahan lahan 121.377 
Jurnal Penyuluhan, September 2014 Vol. 10 No. 2

Tabel 1 Produksi Komoditas Unggulan Tahun 2012 di Kabupaten Banyuwangi

\begin{tabular}{lrrrrrr}
\hline \multicolumn{1}{c}{ Komoditas } & \multicolumn{2}{c}{ Luas (ha) } & \multicolumn{2}{c}{ Produksi (ton) } & \multicolumn{2}{c}{ Produktivitas (ton/ha) } \\
& $\mathbf{2 0 1 1}$ & $\mathbf{2 0 1 2}$ & $\mathbf{2 0 1 1}$ & $\mathbf{2 0 1 2}$ & $\mathbf{2 0 1 1}$ & $\mathbf{2 0 1 2}$ \\
\hline Pangan : & & & & & & \\
Padi sawah & 116.728 & 121.377 & 761.317 & 792.573 & 6,522 & 6,530 \\
Jagung & 29.728 & 22.032 & 189.373 & 141.125 & 6,370 & 6,405 \\
Kedelai & 36.068 & 27.257 & 66.094 & 53.648 & 1,832 & 1,968 \\
Ubi kayu & 2.410 & 1.841 & 46.581 & 35.617 & 19,328 & 19,347 \\
Hortikultura : & & & & & & \\
Jeruk siam & 10.727 & 8.171 & 163.314 & 140.602 & 15,225 & 17,207 \\
Pisang & 4.237 & 3.546 & 107.898 & 79.365 & 25,466 & 22,380 \\
Perkebunan : & & & & & & \\
Kelapa & 23.976 & 23.976 & 128.518 & 155.966 & 5,360 & 6,505 \\
\hline S & & & & & & \\
\hline
\end{tabular}

Sumber: Distanhutbun (data diolah) 2012

Ha. Sedangkan untuk komoditas jagung, terjadi penurunan produksi pada tahun 2011-2012 dari 189.373 ton menjadi 141.125 ton, tetapi ditinjau dari segi produktivitasnya masih mengalami kenaikan meskipun kecil(0,55\%). Penurunan luasan lahanjuga terjadi pada komoditas kedelai, yaitu sebesar 24,4\% dan penurunan produksi sebesar 18,8\%. Dengan melihat potensi yang beranekaragam ini, diperlukan suatu kajian tentang potensi unggulan Kabupaten Banyuwangi agar dapat ditentukan pengembangan komoditas yang tepat. Pemilihan komoditas yang tepat ini akan membantu pencapaian ketersediaan pangan dengan produksi pangan lokal pada Tabel 1 . Data Dinas Pertanian, Kehutanan dan Perkebunan Kabupaten Banyuwangi tahun 2013 menunjukkan pengaruh positif program sekolah lapang pengelolaan tanaman terpadu (SL-PTT) terhadap peningkatan produktivitas hasil tanaman pangan per hektar. Sejalan hasil penelitian Kusmiyati (2010), pembinaan terhadap petani dalam penerapan usahatani dengan metode SLPTT dapat meningkatkan produksi padi dari 4,9 ton/ha menjadi 5,6 ton/ha. Hasil penelitian Marlianti (2008), menunjukkan tingkat kinerja penyuluh pertanian dalam memberdayakan petani relatif kategori cukup. Hal ini disebabkan oleh faktor-faktor yang berpengaruh nyata terhadap kinerja penyuluh pertaniannya sesuai karakteristik sistem sosial (fasilitas agribisnis oleh lembaga pemerintah dan akses petani terhadap kelembagaan agribisnis).

Fakta yang terjadi di Kabupaten Banyuwangi, total jumlah penyuluh pertanian pegawai negeri sipil (PNS) mencapai 119 orang, 100 orang diantaranya berusia lebih dari 50 tahun, sedangkan angkatan kerja berusia 35 tahun cenderung lebih produktif dan inovatif dalam merespon perkembangan teknologi di bidang pertanian. Hasil penelitian ini sesuai dengan teori yang dikemukakan Van de Ban dan Hawkins (1999), usia tenaga kerja produktif berumur 16-64 tahun, sedangkan usia 65 tahun sudah dikatakan usia lanjut. Beban tugas penyuluh, yaitu satu penyuluh menangani 2-3 desa, untuk Kabupaten Banyuwangi terdiri dari 25 kecamatan dan 217 desa.

Berdasarkan surat Menteri Pertanian nomor 593/KP.610/M/11/2011 disebutkan agar teknologi BPTP (Balai Pengkajian Teknologi Pertanian) segera diterapkan ke petani, salah satu strategi Kementerian Pertanian melalui pendekatan satu desa ditangani satu penyuluh, masih belum mencukupi standar yang ditetapkan oleh Kementerian Pertanian. Untuk mencukupi kebutuhan jumlah penyuluh pertanian sesuai surat menteri pertanian di Kabupaten Banyuwangi, dinas pertanian, kehutanan dan perkebunan Kabupaten Banyuwangi membagi tugas dan fungsi penyuluh pertanian. Untuk wilayah perkotaan satu orang penyuluh menangani 2 sampai 3 desa, sedangkan wilayah pedesaan satu desa dipegang 1 sampai 2 orang penyuluh pertanian yang berpengalaman dibidangnya.

Evaluasi kinerja penyuluh pertanian di Kabupaten Banyuwangi terdiri dari tiga tahapan, yaitu persiapan, pelaksanaan dan evaluasi, serta pelaporan program penyuluhan pertanian. Tahap persiapan penyuluhan pertanian menunjukkan bahwa mayoritas memberikan hasil sangat baik $(72,2 \%)$ dan sebagian kecil memberikan hasil cukup 
Tabel 2 Evaluasi Kinerja Penyuluh Pertanian di Kabupaten Banyuwangi

\begin{tabular}{lrrrrrr}
\hline \multirow{2}{*}{ Kinerja Penyuluh Pertanian } & \multicolumn{5}{c}{ Hasil Penilaian (\%) } \\
& Sangat baik & \multicolumn{1}{c}{ Baik } & Cukup & Kurang & Sangat kurang \\
\hline Persiapan & 72,2 & 8,3 & 19,4 & - & - \\
Pelaksanaan & 25,0 & 36,1 & 25,0 & 13,9 & - \\
Evaluasi dan Pelaporan & 5,6 & 30,6 & 22,2 & 38,9 & 2,8 \\
\hline
\end{tabular}

Sumber: Distanhutbun (data diolah) 2013

$(19,4 \%)$ dan baik $(8,3 \%)$. Hasil penilaian pada tahap persiapan inimemenuhi ketentuan. Tahap pelaksanaan penyuluhan pertanian menunjukkan bahwa mayoritas memberikan hasil baik $(36,1 \%)$, tetapi di sisi lain dalam pelaksanaannya masih terdapat hasil kurang, yaitu $13,9 \%$. Pada tahap evaluasi dan pelaporan, mayoritas masih menunjukkan hasil yang kurang (38,9\%). Hasil penelitian Yulianto (2008), sangat perlunya dilakukan evaluasi berkelanjutan terutama terhadap kinerja penyuluh pertanian dalam menjalankan tugas dan fungsinya. Hasil penelitian ini sesuai dengan teori yang dikemukakan Soedijanto (1996), evaluasi sebagai proses urutan rangkaian kegiatan mengukur dan menilai secara sistematis dari program pendidikan dan pelatihan. Oleh karena itu kinerja penyuluh pertanian masih perlu ditingkatkan pelaksanaannya, evaluasi dan pelaporan dalam menjalankan tugas sebagai penyuluh pertanian di Kabupaten Banyuwangi pada Tabel 2.

Berdasarkan uraian tersebut diatas maka permasalahan yang dapat dirumuskan dalam penelitian ini adalah: (1) Faktor-faktor apakah yang memengaruhi peningkatan kinerja penyuluh pertanian di Kabupaten Banyuwangi, (2) Bagaimana strategi peningkatan kinerja prioritas penyuluh pertanian dalam pengembangan agribisnis di Kabupaten Banyuwangi. berdasarkan permasalahan utama, tujuan penelitian ini adalah: (1) Menganalisis faktorfaktor yang memengaruhi peningkatan kinerja penyuluh pertanian di Kabupaten Banyuwangi, (2) Merumuskan strategi peningkatan kinerja prioritas penyuluh pertanian dalam pengembangan agribisnis di Kabupaten Banyuwangi.

\section{Metode Penelitian}

Penelitian ini termasuk dalam penelitian deskriptif, kualitatif dan kuantitatif. Jenis dan sumber data yang digunakan data primer dan data sekunder.
Data primer, yaitu data yang diperoleh langsung dari narasumber. Sedangkan data sekunder, yaitu data yang diperoleh melalui wawancara pihak lain yang berkepentingan dan berkaitan dalam penelitian ini. Waktu pengumpulan data penelitian dilakukan pada bulan Desember sampai dengan Maret 2014. Sedangkan lokasi penelitian yang dipergunakan adalah Dinas Pertanian, Kehutanan dan Perkebunan Kabupaten Banyuwangi. Teknik pengambilan contoh dalam penelitian ini adalah purposive sampling nonprobability, yaitu narasumber dipilih secara sengaja untuk tujuan tertentu dengan menentukan kriteria orang yang dipilih. Kriteria narasumber dari lima pakar ahli di bidang penyuluh pertanian meliputi: Kepala Dinas (Kadis) dan Koordinator penyuluh pertanian (Kabid), Dinas Pertanian, Kehutanan dan Perkebunan, Dekan Fakultas Pertanian Universitas 17 Agustus 1945, Asosiasi Ketua kelompok tani, dan Pengusaha pertanian. Teknik analisis menggunakan IE, SWOT dan QSPM. Waktu pengumpulan data penelitian dilakukan pada bulan Desember sampai dengan Maret 2014. Sedangkan lokasi penelitian yang dipergunakan adalah Dinas Pertanian, Kehutanan dan Perkebunan Kabupaten Banyuwangi.

\section{Hasil dan Pembahasan}

\section{Analisis Lingkungan Internal}

Analisis lingkungan internal dalam penelitian ini bertujuan untuk mengevaluasi kekuatan dan kelemahan internal kinerja penyuluh pertanian di Kabupaten Banyuwangi. Kekuatan dan kelemahan sangat berpengaruh terhadap strategi peningkatan kinerja penyuluh pertanian dalam pengembangan agribisnis di Kabupaten Banyuwangi.

Hasil analisis IFE menunjukkan bahwa kekuatan yang dimiliki oleh penyuluh pertanian umumnya merata dari keempat indikator, tetapi 
Tabel 3 Hasil Analisis IFE

\begin{tabular}{lccc}
\hline \multicolumn{1}{c}{ Faktor-faktor Strategi Internal } & $\begin{array}{c}\text { Bobot } \\
\text { (a) }\end{array}$ & $\begin{array}{c}\text { Ranking } \\
\text { (b) }\end{array}$ & $\begin{array}{c}\text { Skor tertimbang } \\
\text { (axb) }\end{array}$ \\
\hline Kekuatan & & & \\
1. Dukungan program pelatihan & 0,1172 & 3 & 0,3516 \\
2. Gaji sesuai & 0,1266 & 3 & 0,3797 \\
3. SDM berkompetensi & 0,1219 & 3 & 0,3656 \\
4. Fasilitas pendukung memadai & 0,1172 & 3 & 0,3516 \\
Total Kekuatan & 0,4828 & & $\mathbf{1 , 4 4 8 4}$ \\
Kelemahan & & & \\
1. Kurangnya monitoring kinerja penyuluh pertanian & 0,1219 & 2 & 0,2438 \\
2. Jumlah tenaga penyuluh pertanian sedikit & 0,1344 & 2 & 0,2688 \\
3. Semangat kinerja menurun dikarenakan faktor usia ( $\geq 50$ tahun) & 0,1234 & 2 & 0,2469 \\
4. Rendahnya penguasaan teknologi informasi (internet) & 0,1375 & 1 & 0,1375 \\
Total Kelemahan & 0,5172 & & $\mathbf{0 , 8 9 6 9}$ \\
Total Internal & 1,0000 & & $\mathbf{2 , 3 4 5 3}$ \\
\hline
\end{tabular}

indikator adanya kesesuaian gaji mempunyai skor tertinggi dari pada indikator lainnya, yaitu sebesar 37, 97 \%. Hal ini menunjukkan bahwa indikator tersebut memiliki kepentingan relatif tinggi pada faktor kekuatan kinerja penyuluh pertanian dalam pengembangan agribisnis di Kabupaten Banyuwangi. Hasil penelitian Hariadi (2010), bahwa penyuluh semakin produktif apabila penghasilan gaji mencukupi seperti sertifikasi penyuluh, sehingga tidak perlu mencari pendapatan lain. Hasil penelitian Chaudhry (2011), kepuasan gaji berpengaruh positif dengan kepuasan kerja. Kelemahan utama penyuluh pertanian di Kabupaten Banyuwangi adalah indikator rendahnya penguasaan teknologi informasi. Indikator ini mempunyai nilai $13,75 \%$. Hal ini menunjukkan bahwa rendahnya penguasaan teknologi informasi tersebut memiliki kepentingan relatif yang tinggi pada faktor kelemahan kinerja penyuluh pertanian dalam pengembangan agribisnis di Kabupaten Banyuwangi. Hasil analisis IFE disajikan pada Tabel 3.

\section{Analisis Lingkungan Eksternal}

Analisis lingkungan eksternal dalam penelitian ini bertujuan untuk mengevaluasi peluang dan ancaman terkait dengan kinerja penyuluh pertanian di Kabupaten Banyuwangi. Faktor Lingkungan eksternal terdiri atas faktor-faktor peluang yang dapat dimanfaatkan dan faktor-faktor ancaman yang harus diantisipasi oleh pemerintah Kabupaten Banyuwangi dalam pengembangan agribisnis.

Hasil analisis EFE menunjukkan bahwa peluang yang dimiliki oleh penyuluh pertanian umumnya merata dari kelima indikator, tetapi indikator peminat yang menjadi penyuluh pertanian banyak mempunyai nilai skor tertinggi yaitu $42,40 \%$. Hal ini menunjukkan bahwa indikator tersebut memiliki kepentingan relatif tinggi pada faktor peluang kinerja penyuluh pertanian dalam pengembangan agribisnis di Kabupaten Banyuwangi. Ancaman utama pada penyuluh pertanian di Kabupaten Banyuwangi adalah indikator sistem kuota penerimaan jumlah penyuluh pertanian PNS terkait perimbangan APBD. Indikator sistem kuota penerimaan jumlah penyuluh pertanian PNS terkait perimbangan APBD memiliki nilai sebesar $10,20 \%$. Hal ini menunjukkan bahwa kurangnya penerimaan jumlah penyuluh pertanian PNS terkait perimbangan APBD pada faktor ancaman kinerja penyuluh pertanian dalam pengembangan agribisnis di Kabupaten Banyuwangi pada Tabel 4.

\section{Posisi Pengembangan Agribisnis di Kabupaten Banyuwangi}

Berdasarkan klasifikasi pada Tabel 3 dan 4 diketahui bahwa skor total untuk faktor strategi internal adalah 2,3453, sedangkan skor total untuk faktor strategi eksternal adalah 2,5870 menunjukkan 
Tabel 4 Hasil Analisis EFE

\begin{tabular}{lccc}
\hline \multicolumn{1}{c}{ Faktor-faktor Strategi Eksternal } & Bobot & Ranking & $\begin{array}{c}\text { Skor } \\
\text { Tertimbang } \\
\text { (axb) }\end{array}$ \\
\hline Peluang & (a) & (b) & \\
1. Peminat yang menjadi penyuluh pertanian banyak & & & \\
2. Dukungan kebijakan pemerintah daerah & 0,1060 & 4 & 0,4240 \\
3. Peningkatan Jumlah penyuluh pertanian PNS & 0,0970 & 3 & 0,2910 \\
4. Kemajuan teknologi, sehingga mempermudah alih ilmu dan keterampilan & 0,1080 & 3 & 0,3240 \\
5. Penghargaan terhadap penyuluh berprestasi di tingkat nasional & 0,0940 & 3 & 0,2820 \\
Total Peluang & 0,0890 & 4 & 0,3560 \\
Ancaman & $\mathbf{0 , 4 9 4 0}$ & & $\mathbf{1 , 6 7 7 0}$ \\
1. Sistem kuota penerimaan jumlah penyuluh pertanian PNS terkait & & & \\
$\quad$ perimbangan APBD & & & \\
2. Adanya krisis kepercayaan petani terhadap kinerja penyuluh pertanian & 0,1020 & 1 & 0,1020 \\
3. Rendahnya minat masyarakat terhadap sektor pertanian & 0,0990 & 2 & 0,1980 \\
4. Inkonsistensi peraturan/Perundangan & 0,1020 & 2 & 0,2040 \\
5. Tumpang tindih program instansi terkait & 0,0990 & 2 & 0,1980 \\
Total Ancaman & 0,1040 & 2 & 0,2080 \\
Total Faktor Eksternal & $\mathbf{0 , 5 0 6 0}$ & & $\mathbf{1 , 9 1 0 0}$ \\
\hline
\end{tabular}

posisi IFE dan EFE dalam posisi sedang. Hasil matrik IE menunjukkan posisi penyuluh pertanian berada dalam sel V, yaitu Hold and Mantain. Posisi ini menggambarkan bahwa masih perlunya menjaga atau mempertahankan kinerja penyuluh pertanian dalam pengembangan agribisnis di Kabupaten Banyuwangi. Untuk mengetahui gambaran strategi penyuluh pertanian didasarkan pada formulasi IFAS dan EFAS, selanjutnya diperhitungkan dalam Matriks Internal-Eksternal (Matriks IE) pada Gambar 1.

\section{Alternatif Strategi Peningkatan Kinerja Penyuluh Pertanian}

Formulasi alternatif stategi peningkatan kinerja penyuluh pertanian diperoleh dengan menggunakan analisis SWOT. Menurut David (2009), alternatif strategi dibagi menjadi empat bagian, yaitu strategi S-O (strength-opportunities), strategi W-O (weaknesses-opportunities), strategi S-T (strength- threats), strategi W-T (weaknessesthreats). Hasil analisis matrik SWOT, diidentifikasi alternatif strategi yang dapat diterapkan dalam peningkatan kinerja penyuluh pertanian dalam pengembangan agribisnis di Kabupaten Banyuwangi, yaitu (a) Intensifikasi program pelatihan kinerja penyuluh pertanian, (b) melakukan peningkatan kerjasama antar instansi pemerintah, (c) perlunya evaluasi monitoring kinerja penyuluh pertanian tiap enam bulan sekali berdasarkan Tupoksi, (d) meningkatkan mutu penyuluh pertanian di bidang teknologi informasi, (e) pengangkatan penyuluh pertanian THL-TB menjadi PNS, (f) peningkatan kuota penerimaan jumlah penyuluh PNS, (g) koordinasi antar lembaga pemerintah,(h) melaksanakan penguatan program teknologi informasi guna meningkatkan kinerja penyuluh pertanian, (i) peran kelompok tani untuk ikut melaksanakan monitoring kinerja penyuluh pertanian.

\section{Prioritas Strategi Peningkatan Kinerja Penyuluh Pertanian dalam Pengembangan Agribisnis Kabupaten Banyuwangi}

Berdasarkan alternatif strategi yang dihasilkan menggunakan analisis SWOT kemudian dilakukan penilaian terhadap masing-masing alternatif strategi untuk memperoleh prioritas strategi. Penentuan strategi prioritas diperoleh melalui analisis QSPM. 
Tabel 5 Hasil analisis matriks QSPM

\begin{tabular}{clcc}
\hline No & \multicolumn{1}{c}{ Strategi Alternatif } & $\begin{array}{c}\text { Nilai } \\
\text { TAS }\end{array}$ & Prioritas \\
\hline 1 & Intensifikasi program pelatihan kinerja penyuluh pertanian & 6,737 & IV \\
2 & Melakukan peningkatan kerjasama antar instansi pemerintah & 6,622 & V \\
3 & $\begin{array}{l}\text { Perlunya evaluasi monitoring kinerja penyuluh pertanian secara berkala 6 bulan } \\
\text { sekali berdasarkan tupoksi }\end{array}$ & 6,931 & I \\
4 & Meningkatkan mutu penyuluh pertanian di bidang teknologi informasi & 5,950 & IX \\
5 & Pengangkatan penyuluh pertanian THL-TB menjadi PNS & 6,540 & VI \\
6 & Peningkatan kuota penerimaan jumlah penyuluh PNS & 6,886 & II \\
7 & Koordinasi antar lembaga pemerintah & 6,430 & VII \\
8 & $\begin{array}{l}\text { Melaksanakan penguatan program teknologi informasi guna meningkatkan kinerja } \\
\text { penyuluh pertanian }\end{array}$ & 6,769 & III \\
9 & $\begin{array}{l}\text { Peran kelompok tani untuk ikut melaksanakan monitoring terhadap kinerja penyu- } \\
\text { luh pertanian }\end{array}$ & 6,104 & VIII \\
\hline
\end{tabular}

Hasil analisis QSPM menunjukkan prioritas utama yaitu perlunya evaluasi monitoring kinerja penyuluh pertanian secara berkala enam bulan sekali berdasarkan tupoksi, sedangkan strategi alternatif lainnya sebagai pendukung yang hasilnya dimuat pada Tabel 5.

\section{Implikasi Manajerial}

Penelitian ini dilakukan untuk menyusun strategi peningkatan kinerja penyuluh pertanian dalam pengembangan agribisnis di Kabupaten Banyuwangi. Ada tiga tema implikasi manajerial yang dihasilkan dalam penelitian ini adalah: (1) Program pengembangan SDM penyuluh pertanian. Program pengembangan penyuluh pertanian ini berkaitan dengan strategi prioritas berikut: (a) Intensifikasi program pelatihan kinerja penyuluh pertanian. (b) Meningkatkan mutu penyuluh pertanian di bidang teknologi informasi. (c) Peningkatan kuota penerimaan jumlah penyuluh PNS. (d) Melaksanakan penguatan program teknologi informasi guna meningkatkan kinerja penyuluh pertanian.

Berkaitan dengan strategi prioritas tema program pengembangan penyuluh pertanian tersebut, maka dapat dirumuskan strategi: (a) Peningkatan kuota penerimaan jumlah penyuluh PNS dilakukan dengan pengajuan penambahan kuota penyuluh PNS kepada pemerintah Kabupaten Banyuwangi. Pengajuan penambahan ini dilakukan dengan menyertakan pertimbangan hasil dari evaluasi dan monitoring tentang kurangnya penyuluh pertanian di
Banyuwangi. (b) Melaksanakan penguatan program TI guna meningkatkan kinerja penyuluh pertanian dapat dilakukan cara mengadakan pelatihanpelatihan penggunaan komputer dan internet, sehingga informasi dapat tersimpan dengan baik dan arus informasi menjadi lebih cepat. (c) Intensifikasi program pelatihan kinerja penyuluh pertanian dapat dilakukan dengan cara menyusun program kegiatan rutin pelatihan yang bersifat sistematis dan dengan jangka waktu tertentu. Kegiatan pelatihan dapat berupa pelatihan teknik, diklat fungsional berjenjang, motivasi training, kewirausahaan, P4S bagi aparatur dan non aparatur pertanian. (2) Koordinasi dan kerjasama antar instansi. Koordinasi dan kerjasama antar instansi ini berkaitan dengan strategi: (a) Pengangkatan penyuluh pertanian THLTB menjadi PNS. (b) Koordinasi antar lembaga pemerintah. (c) Melakukan peningkatan kerjasama antar instansi pemerintah.

Berkaitan dengan strategi prioritas dengan tema koordinasi dan kerjasama antar instansi tersebut, maka dapat dirumuskan strategi: (a) Melakukan peningkatan kerjasama antar instansi pemerintah dengan cara melakukan kordinasi dengan semua pihak terkait. Koordinasi dilakukan untuk mengintegrasikan semua program kerja, agar tidak terjadi tumpang tindih, sehingga program bisa tepat sasaran. (3) Monitoring kinerja penyuluh pertanian. Monitoring kinerja penyuluh pertanian ini berkaitan dengan strategi prioritas berikut: (a) Perlunya evaluasi monitoring kinerja penyuluh pertanian secara berkala 6 bulan sekali berdasarkan 
tupoksi. (b) Peran kelompok tani (poktan) untuk ikut melaksanakan monitoring terhadap kinerja penyuluh pertanian. Berkaitan dengan strategi prioritas tema monitoring kinerja penyuluh pertanian tersebut, maka dapat dirumuskan strategi sebagai berikut: (a) Perlunya evaluasi monitoring kinerja penyuluh pertanian secara berkala enam bulan sekali berdasarkan tupoksi yang dapat dilakukan dengan menyusun lembar kerja pengawasan kinerja. Lembar kerja berisikan semua indikator-indikator kinerja yang wajib dipenuhi oleh penyuluh. Lembar kerja ini dapat menjadi naskah ilmiah yang ditawarkan sebagai bahan pertimbangan penyusunan kebijakan. (b) Peran poktan untuk ikut melaksanakan monitoring terhadap kinerja penyuluh pertanian dengan cara membuat kuesioner dan menyebarkan secara rutin dengan poktan, sehingga dapat mengetahui pendapat petani secara obyektif tentang kinerja penyuluh pertanian.

\section{Kesimpulan}

Faktor strategik yang mempengaruhi kinerja penyuluh pertanian dalam pengembangan agribisnis di Kabupaten Banyuwangi meliputi faktor internal dan eksternal. Faktor internal adalah indikator kesesuaian gaji sebagai indikator utama pada faktor kekuatan dan indikator rendahnya penguasaan teknologi informasi (internet) sebagai indikator utama pada faktor kelemahan. Faktor eksternal adalah indikator utama minat menjadi penyuluh pertanian cukup banyak sebagai indikator utama faktor peluang. Dan indikator sistem kuota penerimaan jumlah penyuluh pertanian PNS terkait perimbangan APBD sebagai indikator utama faktor ancaman. Implikasi strategi prioritas utama yaitu perlunya evaluasi monitoring kinerja penyuluh pertanian secara berkala 6 bulan sekali berdasarkan tupoksi dengan menyusun lembar hasil kerja pengawasan kinerja, sedangkan strategi prioritas lainnya sebagai pendukung.

\section{Daftar Pustaka}

Muhammad SC, Hazoor MS, Nosheen R, Masood N. 2011. Exploring The Relationship Between Salary Satisfaction And Job Satisfaction: A Comparison Of Public And Private Sektor Organizations. The Journal of Commerce, 3(4):
$1-14$.

[Distanhutbun] Dinas Pertanian Kehutanan dan Perkebunan Kabupaten Banyuwangi. 2012. Peroduksi Komoditas Unggulan dalam Angka. Banyuwangi (ID) : Dinas Pertanian Kehutanan dan Perkebunan Kabupaten Banyuwangi.

[Distanhutbun] Dinas Pertanian Kehutanan dan Perkebunan Kabupaten Banyuwangi. 2013. Evaluasi kinerja Penyuluh Pertanian dalam Angka. Banyuwangi (ID): Dinas Pertanian Kehutanan dan Perkebunan Kabupaten Banyuwangi.

[Distanhutbun] Dinas Pertanian Kehutanan dan Perkebunan Kabupaten Banyuwangi. 2013. Evaluasi Pelaksanaan Pengawalan dan Pendampingan SLPTT dalam Angka. Banyuwangi(ID) : Dinas Pertanian Kehutanan dan Perkebunan Kabupaten Banyuwangi. Fred RD. 2009. Manajemen Strategis (Terjemahan, "Ed ke-12"). Jakarta (ID): Salemba Empat.

Sunarru Samsi H. 2010. Sertifikasi, Disiplin, dan Produktivitas Kerja Penyuluh Pertanian. Jurnal Ilmu-ilmu Pertanian, 2(1): 1-9.

Kusmiyati, Maryani A, Kusnadi D. 2010. Kinerja penyuluhpertanian PNS dalam melaksanakan tupoksi di Kabupaten Bogor (Kasus di BP3K Cibungbulang). Jurnal Penyuluhan Pertanian, 5(1): 1-17.

Marlianti, Sumardjo, Asngari PS, Tjitropranoto P, Saefuddin A. 2008. Faktor-faktor Penentu Peningkatan Kinerja Penyuluh Pertanian dalam Memberdayakan Petani (kasus di Kabupaten Kampar Provinsi Riau). Jurnal Penyuluhan, 4(2): 92-99.

Soedijanto P. 1996. Evaluasi Penyuluhan Pertanian. Jakarta (ID): Universitas terbuka.

Van Den Ban AW, Hawkins HS. 1999. Penyuluhan Pertanian (Terjemahan). Yogyakarta (ID): Kanisius.

Yulianto G, Redono C, Fx. Agus, Kurniawan J. 2008. Evaluasi Program Tenaga Harian Lepas Tenaga Bantu Penyuluh Pertanian (Sebuah penelitian di Provinsi Daerah Istimewa Yogyakarta tahun 2007). Jurnal Ilmu-ilmu Pertanian, 4(1): 61-73. 